\title{
Research and Analysis on Present Situation of Desert Sand Concrete
}

\author{
Ji Yanjun"; Liu Chuang ${ }^{1}$; Ding Zhichao ${ }^{1}$ \\ ( ${ }^{1}$ Shaanxi Key Laboratory of Safety and Durability of Concrete Structures, Xijing University, Xi'an 710123)
}

\begin{abstract}
Due to the rapid development of civil engineering industry, natural medium and coarse sand resources are increasingly scarce. If desert sand is studied and applied in the field of civil engineering, the shortage of sand resources and high unit price can be greatly solved.Therefore, it is very important to study desert sand instead of ordinary sand. Although the application of desert sand in engineering has made rapid development, many engineers and researchers have done a lot of experiments and in-depth research on the physical and chemical properties, mechanical properties and compaction characteristics of desert sand, and also made a lot of experimental research results. However, at present, because of the different engineering properties, different deserts are used and the test methods are different. Generally speaking, the understanding of this special material with engineering properties is not mature at home and abroad, and it is not widely used in civil engineering.
\end{abstract}

\section{Introduction}

Sand, also known as concrete fine aggregate, is a necessary material for construction projects and one of the main components of modern concrete. It plays a role in adjusting the proportion and filling the gap of coarse aggregate in concrete. There are four kinds of sand: river sand, sea sand, desert sand and machine-made sand,

Desert sand, as the name suggests, is sand from the desert. Geographically, the global deserts are concentrated in 13 regions. The total area of deserts in China is about 700000 square kilometers, including the Gobi of more than 500000 square kilometers, which is 1.28 million square kilometers, accounting for $13 \%$ of the total land area of China. The arid area of Northwest China is the most concentrated desert area in China, accounting for about $80 \%$ of the total desert area in China. The main deserts from west to East are Taklimakan Desert, Gurbantonggut desert, Kumtag Desert, Qaidam desert, Badain Jaran Desert, Tengger Desert, Ulan Buh Desert and Kubuqi Desert, with huge reserves of desert sand(Fig.1). The diameter of sand in desert is generally less than $0.25 \mathrm{~mm}$. The fineness of sand in desert is too fine and oily, which is not suitable for construction.

The desert sand is mainly composed of quartz and a small amount of feldspar and muscovite. It is mainly derived from residual minerals of sandstone and granite weathering. The sand in the desert comes from weathering and accumulation, and the harmful substances cannot be removed, which leads to the high content of harmful substances in the sand, which is fine and scattered, and does not meet the standard of construction sand in China.

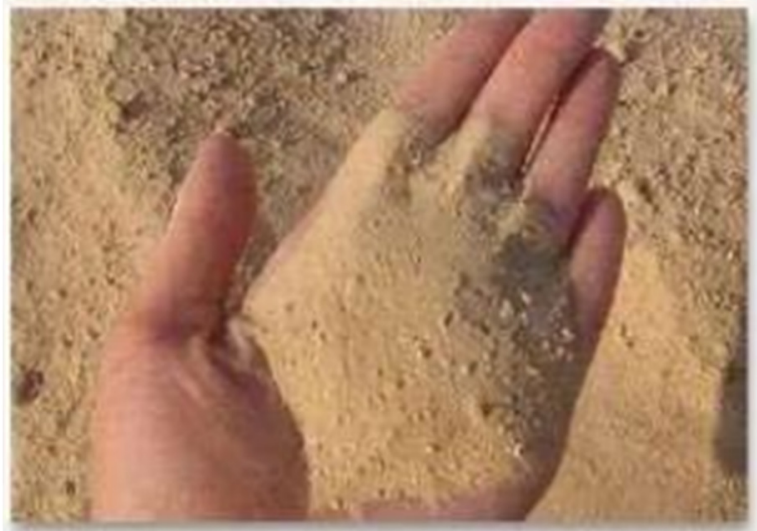

Fig .1 desert sand(Superfine Sand)

Desertification has become a major environmental and socio-economic problem in northern China. The way and degree of land use is the leading factor in the development or reversion of desertification. The increase in the intensity and scope of human economic activities has resulted in the gradual northward movement of the farming pastoral ecotone in northern China, the change of large-scale land use and the reduction of surface vegetation cover, In the past 50 years, the area of desertification in northern China has been expanding continuously, reaching nearly $350000 \mathrm{~km} 2$, and its spreading rate is accelerating, The development and control of land use and desertification process in typical desertification areas were studied

The desert sand is mainly composed of quartz and a small amount of feldspar and muscovite. It is mainly derived from residual minerals of sandstone and granite

Corresponding author: 59772029@qq.com 
weathering. The sand in the desert comes from weathering and accumulation, and the harmful substances cannot be removed, which leads to the high content of harmful substances in the sand, which is fine and scattered, and does not meet the standard of construction sand in China.

With the rapid development of civil engineering industry, the demand for sand and stone resources is increasing. At the same time, sand and stone materials are necessary materials for building concrete, but the sand and stone resources on earth are limited. According to statistics, the unit price per square meter is 300 yuan $/ \mathrm{m}^{2}-400$ yuan $/ \mathrm{m}^{2}$, however, the desert resources on the earth are quite rich and the utilization rate is very low, so the study of desert sand is not only of ${ }^{1}$ great significance to the civil engineering industry to solve the problems of material price and resource shortage, but also to solve desertification and protect the environment.

According to the great development plan of western China, desert sand, as the most abundant and cheapest material in desert area, has the characteristics of good water stability, uniform settlement and no seasonal influence.

There are several reasons why sand in desert can not be used.

First, the sand in the desert does not meet the construction requirements. Generally, concrete is used when building houses (concrete is formed by mixing a certain proportion of sand and cement), which has high strength and can play a great bearing capacity when used to build houses.

Because of the long-term wind erosion, the sand structure in desert is too fine, and its water absorption and fixation are also very poor. Therefore, when it is used in construction, the effect is not good, and the product quality is unqualified, even accidents.

Second, the transportation cost is too expensive. Deserts in China are mainly distributed in Northwest China. As we all know, Northwest China is relatively remote and has poor transportation conditions.

So if you want to transport sand from the northwest to other places, then the transportation cost will be a big problem. It's not cost-effective at all. Moreover, the environment in the desert area is very bad. I believe no one is willing to dig sand there!

Finally, the sand in the desert can only be used after secondary processing, and the cost is high. Due to the large amount of water vapor evaporation in the desert and less rainfall, the alkali content of sand in the desert area is generally very high.

In addition, the sand in the desert is too fine, and there is soil, so it needs to be used after secondary processing. In this way, the cost of sand in the desert is higher, so many scientific research institutions will also use other materials to replace the sand in the desert.

The sand used in daily construction is called River "sand", not desert "sand". Different words lead to different natural uses and properties. Nowadays, river sand, as a kind of resource, is mainly distributed in the river basin. However, with a large number of uncontrolled exploitation, the utilization of natural river sand is generally faced with great difficulty.

\section{Research Status}

\section{1 status quo of domestic research}

Chen Meimei [1-2] studied that desert sand concrete has less application in practical engineering because of its working property. Through orthogonal test, the influence of water-binder ratio, sand content, fly ash content and sand rate on the compressive strength and working property of 28 days was analyzed. Considering the compressive strength and slump, the optimal mix ratio is A4B4C4D3, water / binder ratio 0.40 , sand rate 32 , sand consumption 25 and fly ash 15 . As fine aggregate in concrete, Tengger desert sand can meet the requirements of compressive strength and easiness of concrete.

In order to be able to apply desert sand to mortar and concrete in civil engineering, Zhang [3-6] team tested mortar and concrete made of Tenggri desert sand and Maowusu sand to clarify its engineering characteristics. On the basis of determining the chemical composition and physical characteristics of desert sand, the mechanical properties of mortar and concrete made of two kinds of desert sand as fine aggregate are studied. The experimental results show that desert sand can be used as fine aggregate in mortar and concrete of general civil engineering.

Aiming at the problem of large fineness modulus, high stone content and poor easiness of concrete prepared in Xinjiang region, Liu Juanhong [7-9] team mixed desert sand with coarse machined sand. Liu Juanhong studied the influence of desert sand ratio on fineness modulus and gradation of coarse machined sand, and studied the effects of desert sand on concrete easiness, compressive strength and chloride diffusion coefficient. The results show that the particle gradation of sand is improved well after mixing desert sand and coarse mechanism sand, and the concrete of each grade of mixed sand is better than that of coarse mechanism sand $\mathrm{d} 28$ the compressive strength is $3 \mathrm{MPa} \sim$ higher than that of coarse mechanism sand concrete $\mathrm{MPa}$, and the chloride permeation resistance and carbonization resistance are better than that of coarse mechanism sand.

Medium sand should be preferred in concrete preparation. When coarse sand is used, the sand ratio should be increased and enough cement content should be kept; When fine sand is used, the sand ratio should be reduced appropriately. The sand used for masonry mortar shall meet the technical property requirements of concrete sand. Due to the thin mortar layer, the maximum particle size of sand should be limited. For sand used in rubble masonry, the maximum particle size shall be less than one fourth to one fifth of the thickness of the mortar layer. For brick masonry, medium sand should be used, and the particle size should not be greater than $2.5 \mathrm{~mm}$. For smooth plastering and pointing mortar, fine sand shall be used. 


\section{2 current situation of overseas researchstatus quo of overseas research}

The transient thermal strip method (THS) Saxena [10-11] simultaneously measuring the effective thermal conductivity and diffusivity of particle two-phase materials at atmospheric pressure and room temperature is now used to measure the effective thermal conductivity and diffusivity of rajas than desert sand at different interstitial pressures and room temperature. the experimental values of the effective thermal conductivity and diffusivity at different interstitial air pressures are compared with the estimates using empirical models of the variation of thermal conductivity and diffusivity with interstitial air pressure. in the gap air pressure range of 1 $\mathrm{mm}$ to $760 \mathrm{mmhg}$, the estimates are very consistent with the experimental results, while in the low pressure range $(0.1 \mathrm{~mm}$ to $1 \mathrm{mmhg})$, deviations from the experimental results are observed.

Binner [12] used desert sand after treatment as concrete aggregate, providing a method for producing concrete aggregate and a concrete aggregate. The aggregate is obtained by crushing desert sand in a high-pressure roller press, in which, in the first stage, the desert sand in the bed is crushed by pressure exposure, and then agglomerates are formed. In the second stage, the agglomerates are destroyed by further mechanical exposure. The first stage of pressure exposure is achieved by a single extrusion between two surfaces at pressures in excess of $50 \mathrm{MPa}$. Aggregate produced in this way can significantly improve the strength of concrete compared with the addition of untreated desert sand.

The dynamic mechanical behavior of desert sand concrete is very complex. Yiying W [13] designed a two-dimensional aggregate random distribution program to simulate the dynamic response of desert sand concrete. The influence of coarse aggregate size and volume fraction on dynamic mechanical properties of desert sand concrete is analyzed. The numerical simulation shows that the peak stress of desert sand concrete decreases with the minimum coarse aggregate size. When the maximum size of coarse aggregate is less than $20 \mathrm{~mm}$, the peak stress of desert sand concrete increases with the increase of the maximum size of coarse aggregate. When the maximum size of coarse aggregate is greater than 20 $\mathrm{mm}$, the peak stress of desert sand concrete decreases with the increase of the maximum size of coarse aggregate. With the increase of coarse aggregate volume fraction, the peak stress of desert sand concrete first increases and then decreases.

\section{Particle size analysis of desert sand}

Sand is one of the necessary materials for making concrete, so desert sand as a substitute for ordinary sand, its particle size analysis will be very necessary. The average particle size and content distribution of desert sand are analyzed by laser particle distributor (wet method), as shown in figure 2 below.

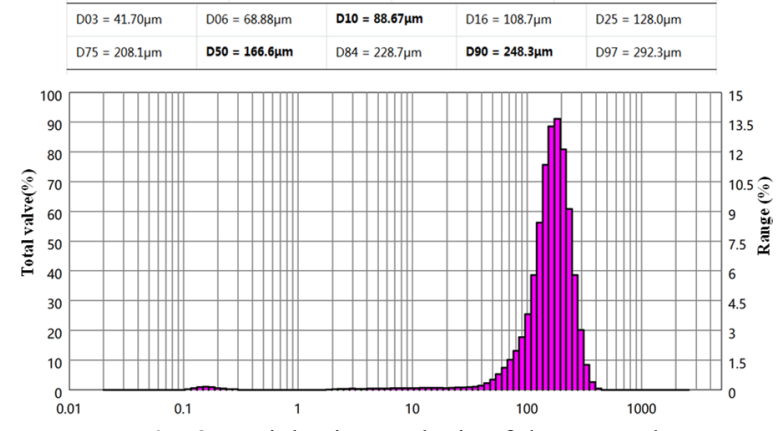

Fig .2 Particle size analysis of desert sand

\section{Development Trend of Desert Sand Concrete}

\subsection{Desert Sand Stability and Curing Technology}

At present, many researchers take the desert sand mixed with lime and fly ash as the research object, through the indoor test, study and analyze the content of lime and fly ash stabilized desert sand as the best mix ratio of base material, base strength and so on, which provides the basis for desert sand to be used as building material. Table 1 below shows that the amount of fly ash is $20 \%$ and the amount of lime is $10 \%$, and its compressive strength has met the design strength requirements. The typical mix ratio of $20 \%$ and $25 \%$ of fly ash was selected to determine the compressive strength of different ages at room temperature and humidity.

Table 1 Experimental results of saturated compressive strength at different ages (MPa)

\begin{tabular}{llll}
\hline Mix Proportion & \multicolumn{2}{l}{ Age $(\mathrm{d})$} & \\
\cline { 2 - 4 } Lime: Fly Ash: & 7 & 40 & 60 \\
Sand & & 1.28 & 1.43 \\
\hline 10:20:70 & 0.72 & 1.28 & 1.41 \\
\hline
\end{tabular}

It can be seen that the strength of the mixture increases with the increase of time, which is because all kinds of reactions in the lime-stabilized desert sand land need time. The longer the time, the safer the reaction and the better the stability effect.

\subsection{Improved stability of curing agent}

Because of the small particle size of desert sand, there are compaction difficulties and poor adhesion in the construction process, which leads to early cracking of concrete and failure to meet the requirements of design strength. Therefore, adding curing agent to prepare desert sand concrete can solve the defect of low adhesion of desert sand.

\section{Conclusion}

The engineering properties of desert sands in China are generally similar, but they are still different. Therefore, 
the physical and chemical properties of desert sands should be studied in different desert areas.

In recent years, the pace of construction in the western region has been gradually accelerated, the application of extra fine sand concrete in various water conservancy projects is more mature, desert sand concrete has also been more used in engineering projects in the western region, but some problems have been exposed in the application process. The study of desert sand, the test and analysis of the basic properties of desert sand, the preparation of new desert sand concrete will be another new breakthrough and application in the future engineering field.

\section{References}

1. Chen Meimei, Song Jianxia, Zhao Wenbo. A Study on the Mechanical Properties of Sand Concrete Mixed with Fly Ash and Tengger Desert [J].]. Ningxia Engineering Technology , 2011,01:61-63

2. Zhu Tengming, Dangtao, Sun Weimin. Experimental Research and Application of Replacing Engineering Sand with Desert Sand [J]. Basic Engineering Material Architectural Science ,1997,(4):26

3. Zhang Guoxue, Yang Jiansen. Experimental Study on the Engineering Properties of Sand in Tenggri Desert [J] Roads ,2003,(8):131-133

4. Yu Yuanfeng, Zhang Xifa, Qiqing first wait. Experimental Study on Engineering Properties of Taklimakan Desert Sand [J] China Desert, 2007, 03:362-366

5. Zhang Cai, Wu Aiqin. Application of Special Fine Sand Concrete Mix Ratio in Sub-Saharan Africa [J] Heilongjiang Traffic Technology ,2007,(5),15-16

6. Cui Dong, Wang Xu. A Study on the Properties of Geilbantong Gute Desert Sands in Xinjiang Water Diversion Project [J] Xinjiang Water Conservancy, 2008,06:8-12

7. Liu Juanhong, Jin Dongmin, Bao Wenzhong, et al. Experimental Study on the Performance of Desert Sand Concrete [J]. Concrete World ,2013(9):66-68

8. Nan Su, Kung-Chung Hsu, His-Wen Chai. A simple mix design method for self-compacting concrete [J]. Cement and Concrete Research. 2001, 31(12): 1799-1807

9. Jin $\mathrm{B} \mathrm{H}$, Song $\mathrm{J} \mathrm{X}$, Liu $\mathrm{H} \mathrm{F}$. Engineering Characteristics of Concrete Made of Desert Sand from Maowusu Sandy Land [J]. Applied Mechanics \& Materials, 2012, 174-177:604-607

10. Saxena N S, Chohan M A, Gustafsson S E . Interstitial Air Pressure Dependence of Effective Thermal Conductivity and Diffusivity of Rajasthan Desert Sand Using Transient Hot-Strip Method [J]. Japanese Journal of Applied Physics, 1987, 26(Part 1, No. 1):51-54

11. Zhang G, Song J, Yang J , et al. Performance of mortar and concrete made with a fine aggregate of desert sand $[\mathrm{J}]$. Building and Environment, 2006, 41(11):1478-1481

12. Binner, Jörg. Use of Treated Desert Sand and as Aggregate for Concrete, 2019

13. Yiying W, Shuhang Z, Haifeng L, et al. Numerical simulation of dynamic failure of desert sand concrete[J]. Concrete, 2016 